\title{
River corridor ventilation analysis and riverfront planning strategy in Tianjin's urban core area
}

\author{
Tong $\mathrm{Ma}^{1}$, Tian $\mathrm{Chen}^{1 *}$ \\ ${ }^{1}$ School of Architecture, Tianjin University, 92 Weijin Road, Nankai district, 300072 Tianjin, Peoples R China
}

\begin{abstract}
River corridors are important potential wind path in cities. This paper took the river in the core area of Tianjin as the research object. By using two ventilation indicators as frontal area index (FAI) and frontal area density (FAD), the overall ventilation and pedestrian level ventilation of riverfront area were quantitatively analyzed. The result showed that contrary to common belief, due to the high FAI of the riverfront area, river corridor in Tianjin's core area did not play the role of wind path but obstructed the wind flow. Also the low FAD indicator of the riverfront area lead to a better outdoor comfort in summer but worse comfort in winter. After verified the correlation between planning indicators (floor area ratio, building height and site coverage) and ventilation indicators, a cluster pattern urban riverfront development mode was proposed. Also a ventilation corridor planning methods based on the river direction and dominant wind direction was suggested. These planning strategy will be more conductive to the wind path and cooling island potential of the river corridors in urban core area.
\end{abstract}

\section{Introduction}

River corridor is precious natural landscape resource in urban area. Meanwhile, it is also urban cooling island and potential wind path. There are many existing studies on river microclimate effects, however, most of those studies focus on the cooling and wetting capacity of urban river corridors [1-4]. As an essential part of microclimate research, ventilation effects of river corridor are less considered. The river runs through cities is always considered as wind path as a matter of course due to its low surface roughness. However, few quantitative researches to support this assumption have been made.

Urban ventilation studies could be classified into three categories by scale: large scale (regional), mesoscale (city) and microscale (urban blacks) [5], as shown in figure 1. As the large-scale studies mainly focuses on regional atmospheric circulation, studies related to the ventilation effect of river corridors are mainly in mesoscale and microscale. Some mesoscale urban ventilation studies [68] point out urban river corridor as a potential main wind path to enhance ventilation in high dense urban area. However, no quantitative analysis is carried out in their studies. Zou et.al [9] conclude Haihe river which flows through the core area of Tianjin can be used as the secondary ventilation corridor to transform cooling air from suburban cool island by using remote sensing. However, those studies did not focus on rivers and mostly used 2-D analyzing tools as remoting sensing but not 3-D analyzing tools. This leads to the current lack of deepness on urban river ventilation research. Moreover, microscale studies, which mostly focus on the permeability of wet and cold air in wind leeward riverfront urban area [10-12], are difficult to systematically discuss the influence of the river on the urban ventilation due to its scale.

Another flaw in existing river ventilation studies is lack of cohesion between mesoscale and microscale [13]. Fortunately, an urban space analysis method based on three-dimensional model has been established in former urban ventilation studies to exam the correlation between urban spatial morphology and ventilation efficiency [1415]. By using this methods, it is possible to establish the relationship between mesoscale and microscale. This method may also adopt in river corridor ventilation researches.

In summary, there are few studies that take rivers and riverfront areas as specific research objects and quantitative analyzed the ventilation effect of river corridors on urban areas in mesoscale. Therefore in this paper, taking Tianjin's core urban area as study area, the influence of river corridor and riverfront urban spatial morphology on urban ventilation will be discussed based on a three-dimension urban model. The findings presented in this work will fill in the research gap in urban river corridor ventilation and provide practical suggestions for urban planning.

*Corresponding author: chentian5561@vip.sina.com 


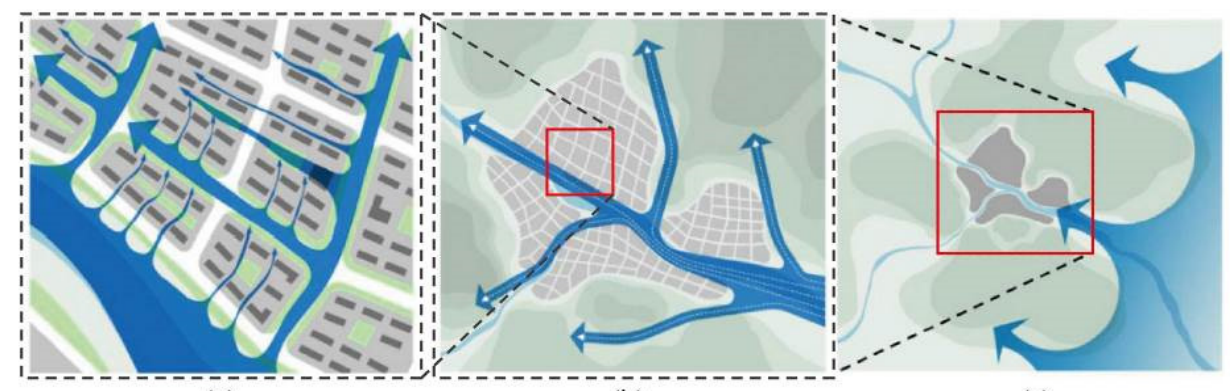

(a)

(b)

(c)

Fig1. Three scale in urban ventilation studies, microscale(a), mesoscale(b) and large scale(c), from Ren [5]
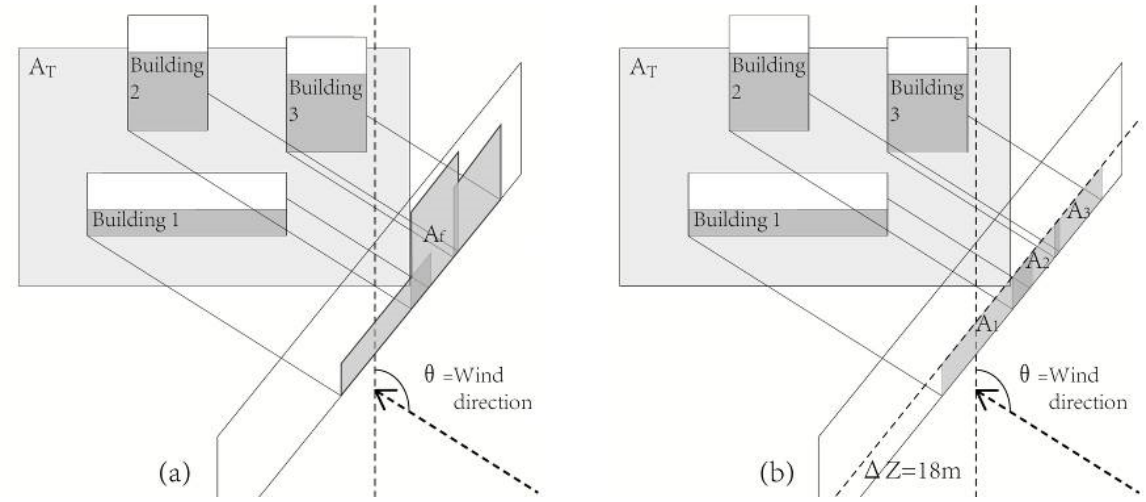

Fig2. The calculation methods of FAI(a) and FAD(b)

\section{Research methods}

\subsection{Ventilation evaluation indicators}

Wind speed is the fundamental index in urban ventilation studies. In this paper, two indicators as the overall wind speed and the pedestrian level wind speed will be selected as the essential index to analyze the effect of river corridor on urban ventilation.

The overall wind speed in urban area is determined by ground roughness when other conditions being equal. The higher the urban development intensity is, the more the windage resistance of buildings are, the higher the ground roughness is, and eventually lower the wind speed passing through the urban area [16]. Although a few indicators could be used to refer ground roughness, Frontal area index (FAI) is widely applied in urban planning field $[9,14,15,17]$. This indicator could accurately reflect the influence of urban canopy morphology and wind direction on the overall wind speed in high dense urban area. The higher the FAI is, the lower the overall wind speed. The formula is shown in eq. 1 , where $\lambda_{f(\theta)}$ represents the frontal area index of a certain area, $A_{F}$ represents the front areas of buildings that face the wind direction of $\theta$, and $A_{T}$ represents the total lot area. Also figure $2 \mathrm{a}$ explain the calculation methods of FAI.

$$
\lambda_{f(\theta)}=\frac{A_{F}}{A_{T}}
$$

Wind speed on pedestrian level, which is another key indicator of urban ventilation, affects human outdoor comfort significantly. Past studies proved that Frontal area density (FAD) has the dominant influence on pedestrian level wind speed $[16,20,21]$. The higher FAD is, the lower wind speed is. Different from FAI, FAD only calculates the front areas of buildings within a certain height above the ground. The formula is shown in eq.2, $\lambda_{f(Z, \theta)}$ represents the frontal area density of a certain area, $\mathrm{A}(\theta)$ represents the area of building surface that approach the wind direction of $\theta$ for a special height ( $18 \mathrm{~m}$ in our study), and $A_{T}$ represents the total lot area, $\mathrm{A}(\theta)=\mathrm{A} 1+\mathrm{A} 2+\mathrm{A} 3+\ldots+\mathrm{An}$. Also figure $2 \mathrm{~b}$ explain the calculation methods of FAD.

$$
\lambda_{f(Z, \theta)}=\frac{\mathrm{A}(\theta)_{\operatorname{proj}(\Delta z)}}{A_{T}}
$$

\subsection{Urban riverfront 3-D model}

The purpose of this paper is to study the influence of river corridor on the ventilation of urban core area. Therefore, three rivers running through Tianjin's core area (Haihe river, Xinkai river and South canal) were selected. The $1000-1500 \mathrm{~m}$ range urban area on both side of the river was selected as study area, as shown in figure $3 \mathrm{a}$. In order to quantitative evaluate the urban space, the study area was divided into grids to aggregate the spatial morphology index in each grid. There have been two aggregation methods used in past research. One is to aggregate buildings according to building blocks [20]. The other method involves manipulation of data using regular grids, which is commonly used in structural data related to urban ventilation $[14,15]$. Regular grids method was used in this paper due to river corridor cannot be divided into 


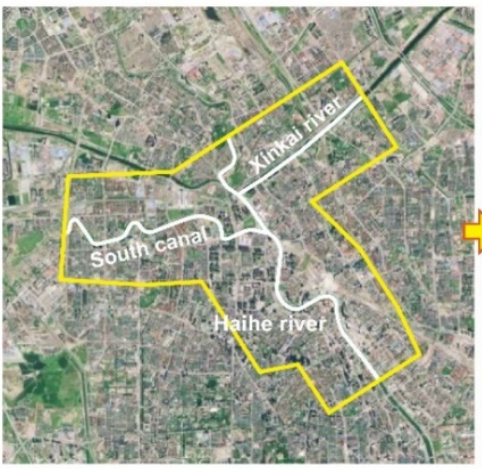

(a)

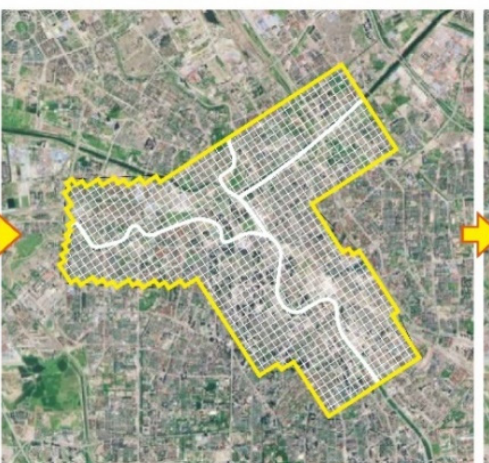

(b)

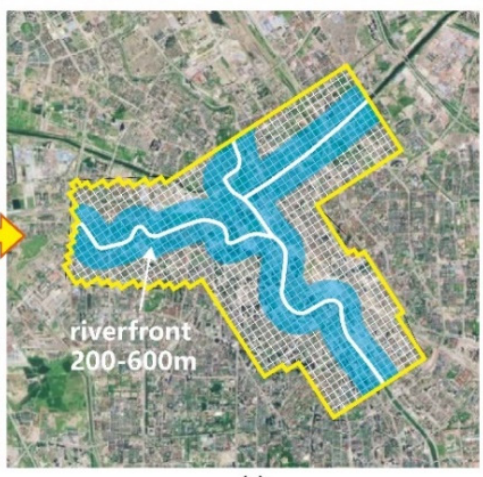

(c)

Fig3. Study area(a), grid partition(b) and the range of riverfront area(c)

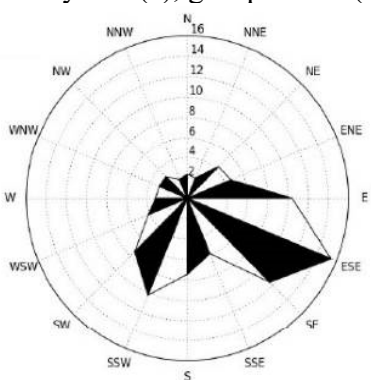

(b)

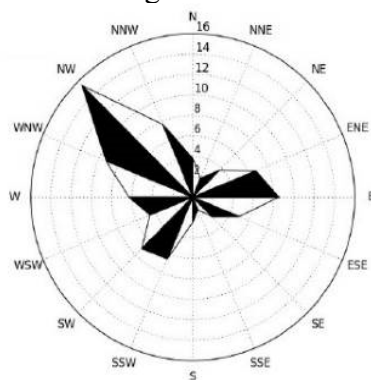

(c)

Fig4. The wind direction of summer(a) and winter(b) in study area

any building blocks. As shown in figure $3 \mathrm{~b}$, study area was divided into 1130 regular grids with the size of $200 \mathrm{~m} * 200 \mathrm{~m}$. The FAI and FAD of each grid was calculated both in winter and summer. The overall FAI and FAD of urban riverfront area in $200 \mathrm{~m}, 400 \mathrm{~m}$ and $600 \mathrm{~m}$ distant to the river (figure 3c) were calculated and compared with the whole study area. The spatial morphology difference between riverfront area and other urban area was compared to discussed the influence of river corridor on urban overall ventilation and pedestrian level ventilation. According to the meteorological data of Tianjin Meteorological Bureau in the past 15 years, Tianjin city's dominant wind direction is southeast by east in summer (figure 4a) and northwest in winter (figure 4b). Thus the FAI and FAD of study area in summer and winter were calculated respectively and then averaged.

\section{Results and analysis}

\subsection{Overall ventilation analysis}

The average FAI of every block in riverfront area within $200 \mathrm{~m}, 400 \mathrm{~m}$ and $600 \mathrm{~m}$ range of the river corridor were calculated to identify if there are any spatial morphology difference between riverfront area and non-waterfront area, both in summer and winter, as shown in figure 5. The results showed that in summer, FAI of all study area (5a), riverfront $600 \mathrm{~m}$ range $(5 \mathrm{~b})$, riverfront $400 \mathrm{~m}$ range $(5 \mathrm{c})$ and riverfront $200 \mathrm{~m}$ range $(5 \mathrm{~d})$ were respectively 0.131 , $0.138,0.137$ and 0.140 , and FAI beyond riverfront $600 \mathrm{~m}$ range was 0.124 . Meanwhile in winter, FAI of all study area $(5 \mathrm{e})$, riverfront $600 \mathrm{~m}$ range $(5 \mathrm{f})$, riverfront $400 \mathrm{~m}$ range $(5 \mathrm{~g})$ and riverfront $200 \mathrm{~m}$ range $(5 \mathrm{~h})$ were respectively $0.129,0.136,0.135$ and 0.140 , and FAI beyond riverfront $600 \mathrm{~m}$ range was 0.122 . It could be seen that FAI in riverfront area are nearly 0.15 higher than nonriverfront area and FAI are highest in riverfront $200 \mathrm{~m}$ range area, both in summer and winter.

Furthermore, the distribution of blocks that had a higher and lower FAI than the average within riverfront $600 \mathrm{~m}$ range were mapped, as shown in figure 6 . As the blocks with a lower FAI than the average value facilitating the natural ventilation while the blocks with a higher FAI than the average obstructing the natural ventilation, the relationship between the riverfront area and the ventilation corridor could be analyzed. It could be seen that the blocks obstructing ventilation were evenly distributed along the river in high dense riverfront areas. Meanwhile, the blocks facilitating ventilation showed little continuity. The only exception was the area around Tianjin railway station. The FAI of this area was obviously lower than surroundings and a wind corridor was formed due to the open space made by railways.

To sum up, the rivers in the urban core area of Tianjin didn't promoted urban ventilation due to the high FAI in riverfront area. In contrast, it slightly lowered the overall ventilation of urban core area. Moreover, the river corridor in Tianjin did not reach its potential in wind corridor as the high FAI blocks were linear distributed along the river, which was contrary to existing researches $[8,9]$.

\subsection{Pedestrian level ventilation analysis}

The average FAD of every block in riverfront area within $200 \mathrm{~m}, 400 \mathrm{~m}$ and $600 \mathrm{~m}$ range of the river corridor 


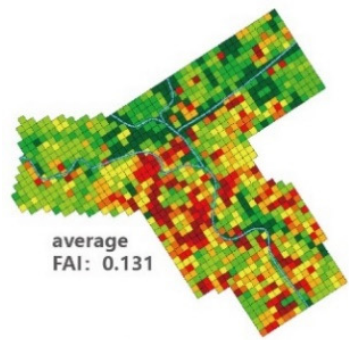

(a) all area-summer

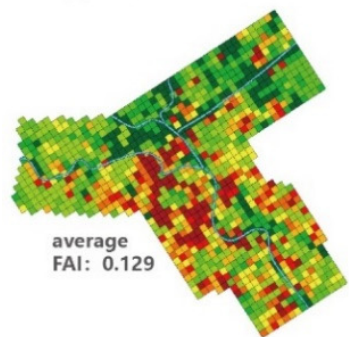

(e) all area-winter

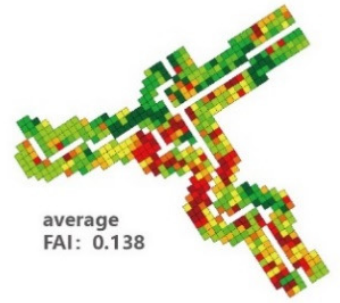

(b) $600 \mathrm{~m}$ range-summer

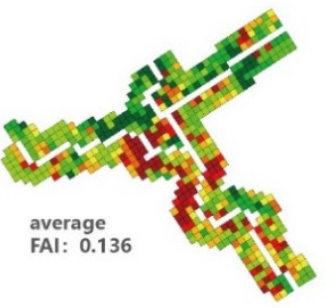

(f) $600 \mathrm{~m}$ range-winter

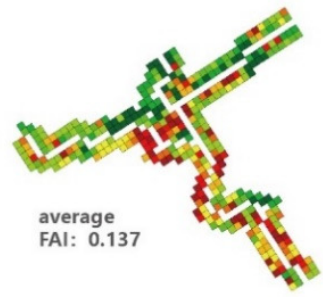

(c) $400 \mathrm{~m}$ range-summer

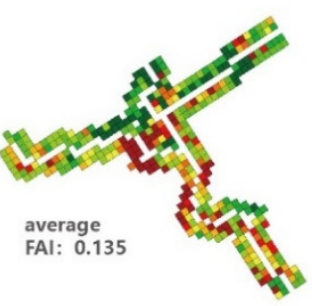

(g) 400m range-winter

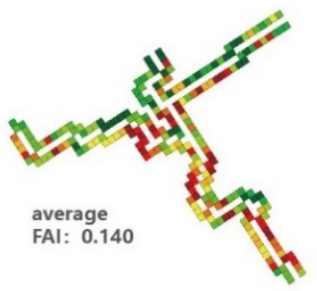

(d) $200 \mathrm{~m}$ range-summer

Fig5. FAI in whole study area and in different riverfront range
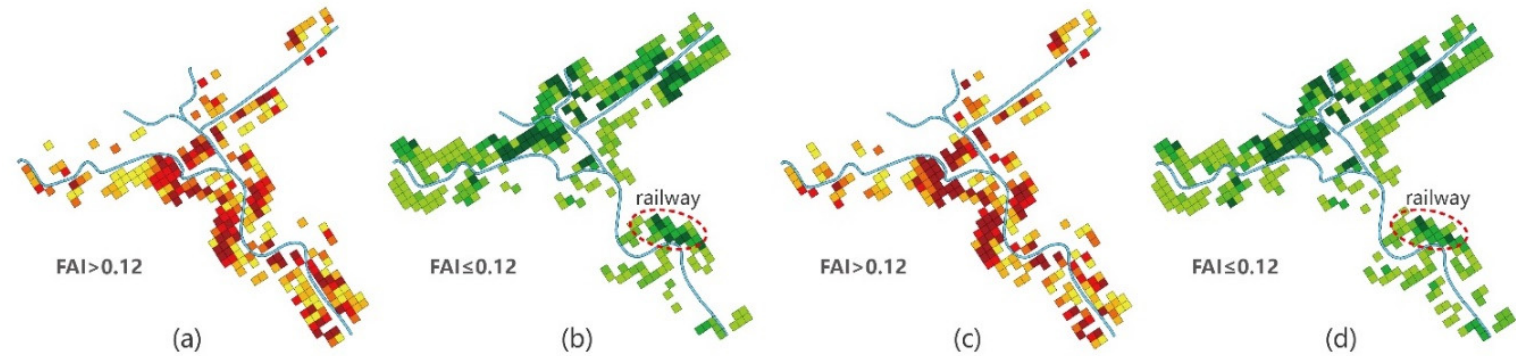

Fig6. In 600m range, FAI higher than average (a) and lower than average (b) in summer, and FAI higher than average (c) and lower than average (d) in winter

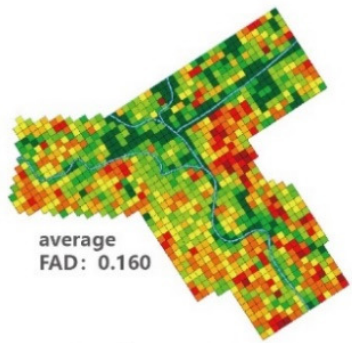

(a) all area-summer

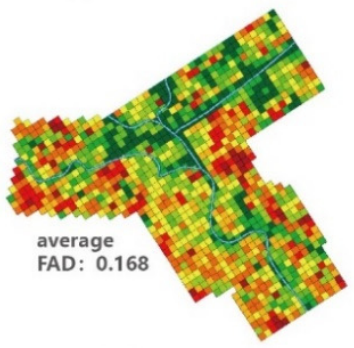

(e) all area-winter

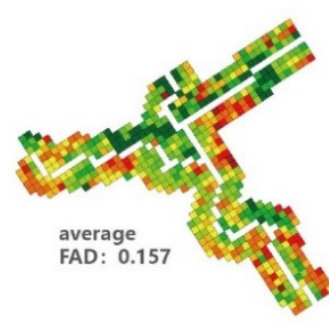

(b) $600 \mathrm{~m}$ range-summer

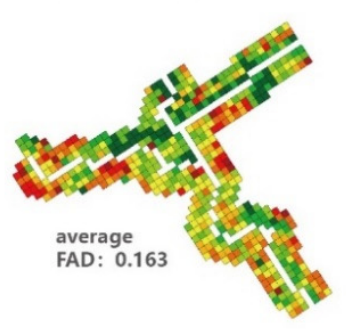

(f) $600 \mathrm{~m}$ range-winter

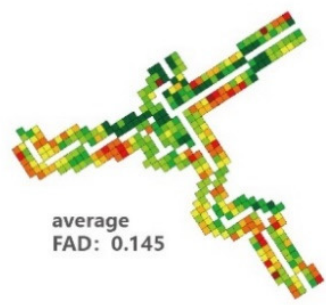

(c) $400 \mathrm{~m}$ range-summer

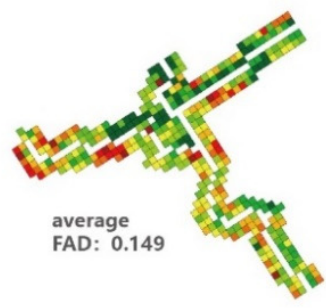

(g) $400 \mathrm{~m}$ range-winter

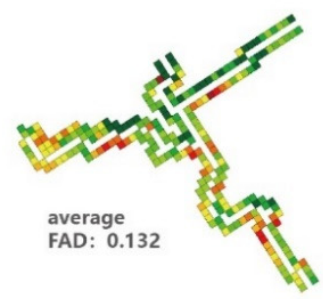

(d) $200 \mathrm{~m}$ range-summer

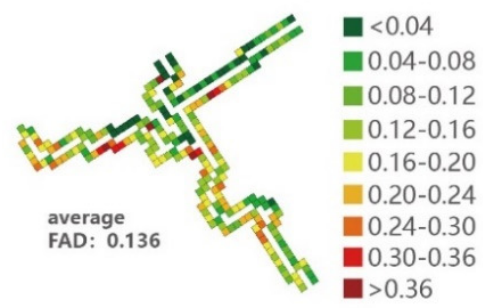

(h) $200 \mathrm{~m}$ range-winter

Fig7. FAD in whole study area and in different riverfront range

were calculated to analyse the effect of river corridor on pedestrian level wind condition in riverfront area, both in summer and winter, as shown in figure 7 . The results showed that in summer, FAD of all study area (7a), riverfront $600 \mathrm{~m}$ range $(7 \mathrm{~b})$, riverfront $400 \mathrm{~m}$ range $(7 \mathrm{c})$ and riverfront $200 \mathrm{~m}$ range $(7 \mathrm{~d})$ were respectively 0.160 , $0.157,0.145$ and 0.132 , and FAD beyond riverfront $600 \mathrm{~m}$ range was 0.163 . Meanwhile in winter, FAD of all study area (7e), riverfront $600 \mathrm{~m}$ range (7f), riverfront $400 \mathrm{~m}$ range $(7 \mathrm{~g})$ and riverfront $200 \mathrm{~m}$ range $(7 \mathrm{~h})$ were 


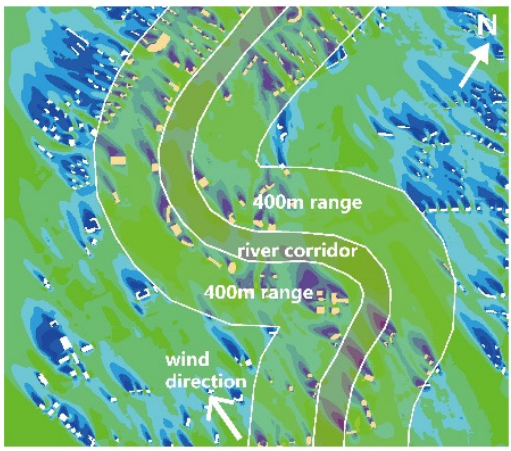

(a)

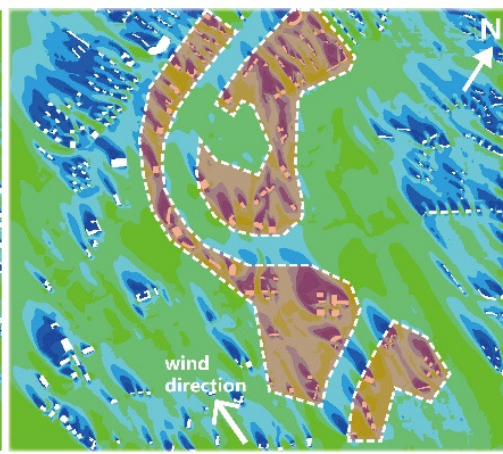

(b)

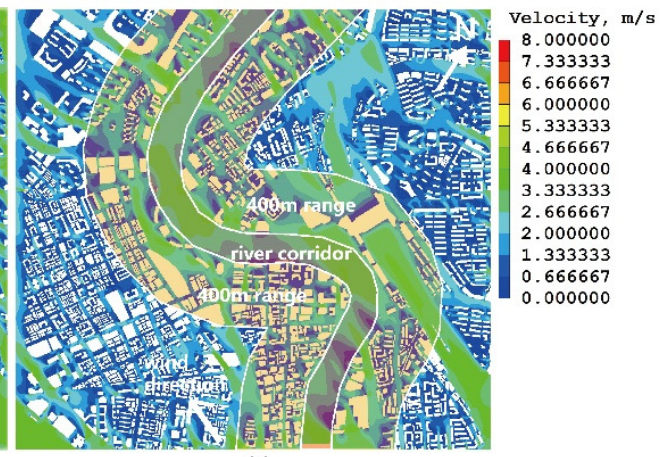

(c)

Fig8. Simulation result of wind speed at $27 \mathrm{~m}$ height of $400 \mathrm{~m}$ riverfront range(a), buildings obstruct ventilation(b) and wind speed at $1.5 \mathrm{~m}$ height of $400 \mathrm{~m}$ riverfront range $(\mathrm{c})$

respectively $0.168,0.163,0.149$ and 0.136 , and FAD beyond riverfront $600 \mathrm{~m}$ range was 0.173 . It was obvious that the FAD of riverfront area was significantly lower than non-riverfront area. The closer the area was to the river, the lower the FAD was. This caused the higher pedestrian level wind speed in riverfront area than nonriverfront area, especially in river banks. This enhanced the outdoor comfort on riverfront area in summer and reduced the comfort in winter, which was consistent to real feelings.

\subsection{Numerical simulation analysis}

To validate the ventilation efficiency indicators set in this paper, computational fluid dynamic numerical simulation was carried out to verify the relationship between spatial morphology and wind speed. K- $\varepsilon$ turbulence model that commonly used in urban microclimate studies was selected. The simulation area was about $4000 \mathrm{~m} * 4000 \mathrm{~m}$ within the study area. The initial wind speed at $10 \mathrm{~m}$ was $2.8 \mathrm{~m} / \mathrm{s}$, the wind direction was southeast to east, the model resolution was $5 \mathrm{~m}$ and the urban roughness length was $0.75 \mathrm{~m}$.

Figure $8 \mathrm{a}$ shows the wind speed at $27 \mathrm{~m}$ height of the simulation area. According to the statistics of the proportion of different wind speed intervals, the wind speed within river corridor was $2.55 \mathrm{~m} / \mathrm{s}$, the wind speed within $400 \mathrm{~m}$ range of riverfront area was $2.54 \mathrm{~m} / \mathrm{s}$ and the wind speed outside $400 \mathrm{~m}$ range of riverfront area was $2.56 \mathrm{~m} / \mathrm{s}$. As a result, river corridor had not promoted ventilation in high dense urban area as the wind speed in each area were almost the same. Figure $8 \mathrm{~b}$ proved the area with high-rise buildings and high FAI caused the low wind speed zone within river corridor and wasted the ventilation potential of the river.

Figure $8 \mathrm{c}$ showed the wind speed at $2 \mathrm{~m}$ height of simulation area. According to the statistics of the proportion of different wind speed intervals, the wind speed within river corridor was $2.12 \mathrm{~m} / \mathrm{s}$, the wind speed within $400 \mathrm{~m}$ range of riverfront area was $1.69 \mathrm{~m} / \mathrm{s}$ and the wind speed outside $400 \mathrm{~m}$ range of riverfront area was $1.55 \mathrm{~m} / \mathrm{s}$. This verified the higher pedestrian level wind speed in riverfront area than non-riverfront area due to its lower FAD.

\section{Riverfront planning methods for ventilation optimization}

By analyzing the value and distribution of FAI and FAD indicator of different range of riverfront area, this study figured out the influence of river corridor on the overall ventilation and pedestrian level ventilation for high dense urban area in Tianjin. The results are as below: 1) different from previous studies, instead of promoting ventilation, rivers in Tianjin's high dense urban area has a negative contribution on urban ventilation. 2) the potential of rivers as ventilation corridors and cold island effects cannot be realized due to the high FAI blocks along the river obstructed the air flow. 3) the low average FAD of riverfront area lead to higher pedestrian wind speed. As the pedestrian level wind speed is relatively high within river corridor than other urban area, the riverfront area is more comfortable in summer but less comfortable in winter.

\subsection{Using planning indicator to optimize riverfront ventilation}

The FAI and FAD could accurately reflect the effect of urban spatial morphology on ventilation. However, the calculation methods of those two indicators have to consider about the wind direction, building direction and building location in site. So it is difficult to use FAI and FAD in the early stage of urban planning practice. Therefore, the correlation between FAI/FAD and planning indicators as floor area ratio (FAR), building height $(\mathrm{BH})$ and site coverage (SC) were established. The purpose is to reveal if FAI/FAD could be replaced by these planning indicators to optimize riverfront wind environment more convenient.

Figure 9a indicates that FAI is significantly positively correlated with FAR, with a Pearson correlation coefficient 0.886 . Figure $9 \mathrm{~b}$ indicates that FAD is weak positively correlated with FAR, with a Pearson correlation coefficient 0.489 . The dispersion degree of FAD rapidly enhanced as FAR increase. Figure 9c indicates that FAI is significantly positively correlated with $\mathrm{BH}$, with a Pearson correlation coefficient 0.793 . The FAI of some blocks dispersed when $\mathrm{BH}$ is high. 

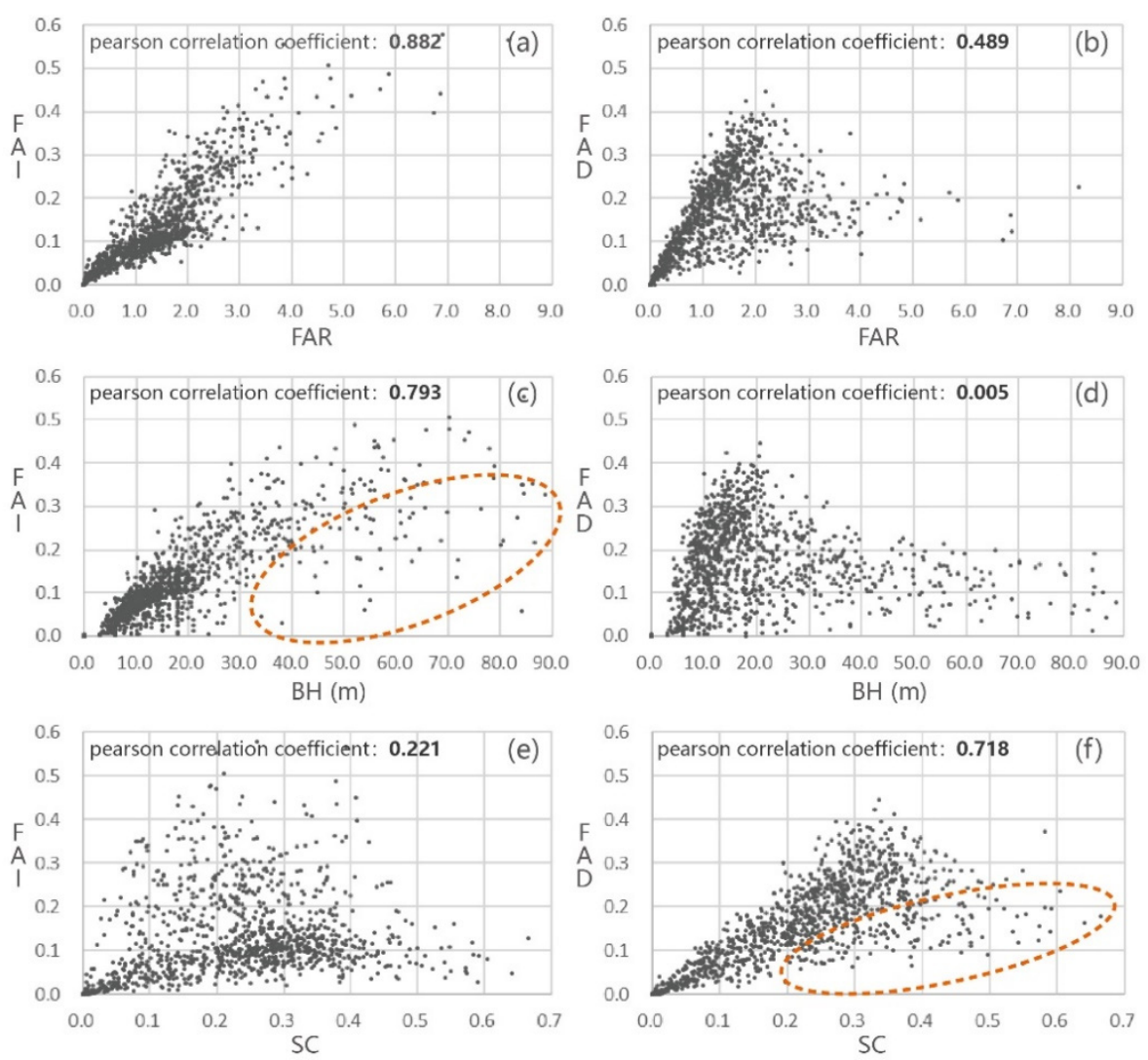

Fig9. The correlation and scatter diagram between planning index(x axis) and ventilation index(y axis)

These blocks have a common feature: small number of high-rise buildings. This caused these blocks with a high $\mathrm{BH}$ and a low FAI. This happens mainly because of the errors caused by the grid division, which is tolerable. Figure $9 \mathrm{~d}$ indicates that FAD is not correlated with $\mathrm{BH}$, with a Pearson correlation coefficient 0.005 . Figure 9e indicates that FAI is not correlated with SC, with a Pearson correlation coefficient 0.258 . Figure $9 f$ indicates that FAD is significantly positively correlated with $\mathrm{SC}$, with a Pearson correlation coefficient 0.740 . The FAD of some blocks dispersed when SC is high. These blocks had the following features: 1) high site coverage with a low average building height and 2) a single building with a huge floor area. This two features will cause the low FAD with a high $\mathrm{SC}$ in blocks.

Therefore, in urban planning practice, FAR and $\mathrm{BH}$ could replace FAI to control the overall ventilation. In master planning, FAR is the essential indicator to controlling urban development intensity. So it is possible to optimize the riverfront wind environment by controlling the FAR of each urban block in the riverfront area in the early planning stage. $\mathrm{BH}$ could be used as a secondary indicator in skyline control or height limitation. The strong correlation between FAD and SC mean it is possible to effectively adjust the pedestrian level wind environment by controlling site coverage of a block. However, it should be noted that it is less useful to use this method when there are blocks with low-rise building clusters or buildings with huge floor plan area such as shopping malls on riverfront area. For these two kind of blocks, FAD need to be considered as a planning indicator directly.

\subsection{Planning strategy of urban riverfront area}

1) cluster riverfront layout mode. Many past studies suggest that low development intensity urban blocks with low building height and low site coverage should be located on both side of the wind corridors to help enhance the ventilation efficiency. Although this approach is rational theoretically, it is impractical in planning practice. Due to the urban development intensity is more determined by its land value, it is not possible to reduce the development intensity as the riverfront area has a more valuable natural landscape resources. The high natural landscape value causes the high FAR and further reduces the ventilation efficiency on riverfront area. Therefore, a cluster pattern of urban riverfront development is suggested in this study, as shown in figure 10. The blocks with high development intensity and building heights clustered as the overall FAR of the riverfront area stay the same. Meanwhile, the open space and block with low development intensity could be located between clusters. This could help the wind path cross the river and bring cold and humid air into the riverfront urban area to reduce urban heat island. For urban redevelopment area, FAR award and FAR transfer policy could be applied in blocks located in wind path to encourage a development mode with low building height and low density.

2) Planning urban wind corridor with river direction. River has a cooling and humidifying effect as well as its low surface roughness for ventilation. The microclimate effect of rivers can be maximized when cooling, humidification and ventilation effect combined. 


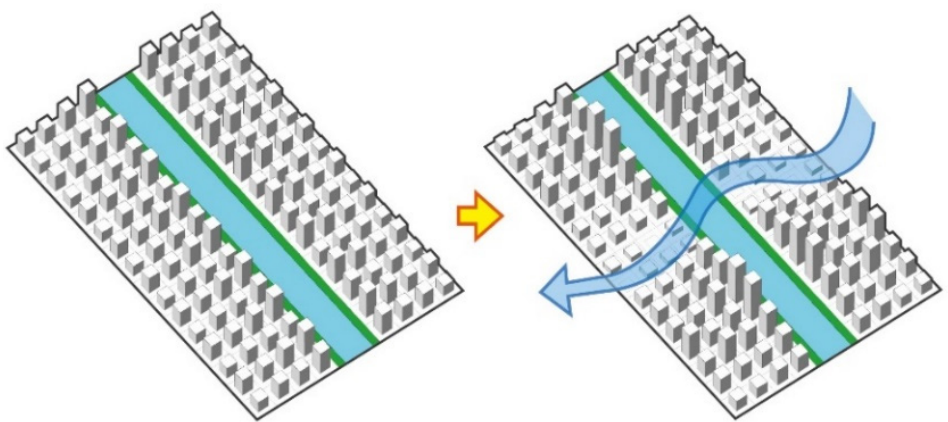

Fig10. From linear pattern to cluster pattern development on riverside area
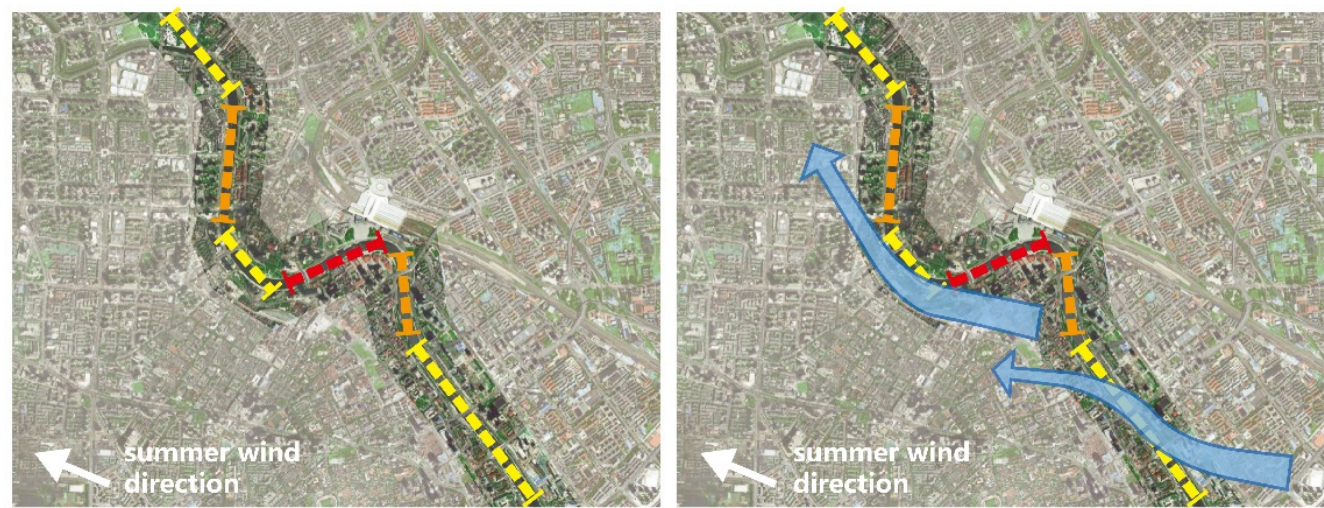

-=| high ventilation potential $\vdash=\mid$ mid ventilation potential $\vdash=\mid$ low ventilation potential $\nleftarrow$ wind path

Fig11. Ventilation potential of river sections with different river-wind direction angle

However, as most rivers are natural formed, not all rivers have the potential to be wind path. Givoni [21] point out that the wind path is effective only if the angle between the wind path and wind direction less than $30^{\circ}$. Hence, when planning wind corridors, the rivers should be divided into several sections based on the its direction. The ventilation potential of each river section could be realized after figure out the angle between each river section and dominant wind direction, as shown in figure 11 . Then the high ventilation potential section should be integrated into urban wind corridor system. As a result, the wind corridor will pass through more area of waterbody and bring cold and humid air into urban high dense area to alleviate urban heat island.

3) Different urban spatial morphology control on windward and leeward side of river. The riverfront area has a higher FAI and a lower FAD than other urban area, which means a low-dense and high-rise building arrangement is more popular in riverfront area. The reason for this condition is the maximum utilization of river landscape resources in urban development to enhance land value. However, the increase of building height will lead to the increase of wind dispersion and wind turbulence around the corner of tall buildings in pedestrian level [19]. Combined with the relatively high wind speed, this will cause the poor pedestrian level wind condition on riverfront area in winter. therefore, in planning practice, the windward and leeward riverfront area should set different planning strategy according to seasonal wind direction. Taking Tianjin as an example, it needs ventilation in summer and wind obstruction in winter. Thus in winter, the leeward riverfront should enhance the site coverage and lower the average building heights to reduce the pedestrian level wind speed and wind turbulence. A traditional development mode with high site coverage and narrow street is recommended and the podium of the high-rise building is a must. Meanwhile in summer, the leeward riverfront should reduce the site coverage to enhance the pedestrian level wind speed to allow cold and humid air penetrating into inner urban areas. Also the limitation for building height could be liberalized.

\section{Conclusion}

Taking Tianjin's urban core area as the research site, this study used two key indicators as FAI and FAD to analyze the effect of river corridor on urban ventilation. The following conclusions could help urban planners to understand the ventilation condition of riverfront area and develop targeted planning strategies. 1) different with past studies, this paper proved that river corridor in Tianjin's urban core area didn't promoting riverfront ventilation. On the contrary, it obstructed the wind path because of the high development intensity and high FAI on riverfront area. 2) the low FAD increased the pedestrian level wind speed in river banks which is conductive to summer ventilation but worsen the wind environment in winter. 3) FAR and building height were significantly positively correlated with FAI and site coverage was significantly positively correlated with FAD. These three planning indicators could be used to control riverfront wind environment in early planning stage. 4) in order to maximize the microclimate effect of the river, a cluster mode of riverfront urban development mode is proposed to promoting air flow through the river. 5) river sections 
that have a small angle with dominant wind direction should be considered as wind path and considered as part of the urban wind corridor system. 6) different spatial morphology planning methods should be applied in windward and leeward side of rivers according to the dominant wind direction in different seasons.

\section{References}

1. K. Yang, M. Tang, Y. Liu, et al. Analysis of microclimate effects around river and waterbody in Shanghai urban district. Journal of East China Normal University (Natural Science) 03: 105-114 (2004)

2. E.A. Hathway, S. Sharples. The interaction of rivers and urban form in mitigating the Urban Heat Island effect: A UK case study. Building and Environment 58: 14-22 (2012)

3. H. F. Li, Y. S. Li, Z. Lu, et al. Analysis on the thermal environment effect of river corridor landscape. Geography and Geo-information science 31(04): 5154+133 (2015)

4. Z. Cai, G. F. Han, M. C. Chen. Do water bodies play an important role in the relationship between urban form and land surface temperature?. Sustainable Cities and Society 39: 487-498 (2018)

5. C. Ren, R. Yang, C. Cheng, et al. Creating breathing cities by adopting urban ventilation assessment and wind corridor plan-The implementation in Chinese cities. Journal of Wind Engineering and Industrial Aerodynamics 182: 170-188 (2018)

6. H. Z. Xi, S. Jiao, L. Y. Lu. Research on the mode of creating urban natural ventilation channel for the areas where its hot in summer and cool in winter-take Changsha as an example. Huazhong Architecture 28(06): 106-107 (2010)

7. J. Y. Li, X. H. Li, R. B. Xiao. Research on the planning and control method of urban ventilation corridors- a case study of regulatory planning of Baiyun new town, Guangdong. Landscape Architecture 05: 92-96 (2014)

8. S. P. Zeng. Research on the theory of "source-flowsink" ventilation corridor system construction and planning strategy-the case of the center districts of Tianjin. PHD thesis, Tianjin University (2016)

9. Z. Zou, J. Kang, Z. Y. Zhou, et al. Construction and control of ventilation corridors in the main urban area of megalopolis: a case of Tianjin. Building Science 35(06): 91-97+107 (2019)

10. J. Wang, Research on building layout strategy in riverfront of Shenzhen on wind environment. MSC thesis, Harbin Institute of Technology (2012)

11. X. C. Song, J. Liu, L. Yu. Impact analysis of riverfront residential building design in northern region on the thermal and humid environment in summer. Building Science 31(06): 14-19 (2015)

12. D. X. Zhang. Research on optimization strategy of wind environment in urban waterfront based on source and flow concept. MSC thesis, Shenyang
Jianzhu University (2018)

13. W. W. Wang, F. N. Li, D. Wang. A review and trend of urban ventilation channel research. Urban Problems 02: 36-40 (2018)

14. E. Ng, C. Yuan, L. Chen, et al. Improving the wind environment in high-density cities by understanding urban morphology and surface roughness: A study in Hong Kong. Landscape and Urban Planning 101(1): 0-74 (2011)

15. C. M. Hsieh, H. C. Huang. Mitigating urban heat islands: A method to identify potential wind corridor for cooling and ventilation. Computers Environment \& Urban Systems 57: 130-143 (2016)

16. T. T. Li. Research on the construction and planning of urban ventilation based on urban morphology and surface roughness - a case study of Shenzhen, China. MSC thesis, Shenzhen university (2017)

17. C. S. B. Grimmond, T. R. Oke. Aerodynamic properties of urban areas derived from analysis of surface form. J. Appl. Meteorol. 38: 1262-1292 (1999)

18. C. Yuan, C. Ren, E. Ng. GIS-based surface roughness evaluation in the urban planning system to improve the wind environment - A study in Wuhan, China. Urban Climate 10: 585-593 (2014)

19. T. Ma, T. Chen. Classification and pedestrian-level wind environment assessment among Tianjin's residential area based on numerical simulation. Urban Climate 34: 100719 (2020)

20. T. Gál, J. Unger. Detection of ventilation paths using high-resolution roughness parameter mapping in a large urban area. Building \& Environment 44(1): 198206 (2009)

21. B. Givoni. Climate considerations in building and urban design. Van Nostrand Reinhold (1998) 